\title{
Regional left ventricular wall motion in pacing induced angina
}

\author{
J R DAWSON, D G GIBSON \\ From Brompton Hospital, London
}

SUMMARY Left ventricular cineangiograms ( $30^{\circ}$ right anterior oblique projection) and high fidelity left ventricular pressure were recorded at rest in 10 individuals with normal hearts and at rest and during an episode of angina provoked by rapid atrial pacing in 14 patients with obstructive coronary artery disease. Angiograms were digitised frame by frame. The ventricular perimeter was divided into 40 segments and regional ventricular function was examined by means of isometric and contour plots and by the construction of segmental pressure-wall displacement loops. In 10 patients 12 abnormal resting regions were identified. The commonest ( 11 regions) was delayed onset of inward endocardial motion during systole which was manifest by diagonal contour lines on the contour plot. Six regions (five with associated delay in onset of inward motion) showed resting hypokinesis. Angina was associated with the development of 19 new regions of abnormal wall motion in 12 patients. Fourteen of these regions of abnormality were thought to be primary events occurring as a consequence of ischaemia and five to be secondary events occurring in normally perfused regions of myocardium. Hypokinesis occurred in 12 regions, developing in a region with normal amplitude at rest in seven and as an extension of resting hypokinesis in five. In 10 out of 12 cases the region of hypokinesis developed in a region showing diagonal contour lines at rest. Asynchrony with delay in the timing of peak inward displacement relative to minimum volume occurred with angina in eight regions (in six cases concomitent with hypokinesis and in two cases in isolation). In contrast with hypokinesis the pattern of wall motion at rest did not permit regions developing asynchrony with angina to be identified.

Pressure-displacement loops show that regional hypokinesis is associated with reduced segmental work and that regional asynchrony (delayed or premature timing of peak inward endocardial displacement) is associated with a loss of efficiency of energy transfer between the myocardium and the circulation. These observations illustrate the complex nature of wall motion abnormalities occurring with angina.

Regional myocardial ischaemia is believed to develop during episodes of angina in patients with coronary artery disease. A well documented consequence of ischaemia is hypokinesis in the affected region which can be demonstrated by contrast or radionuclide angiography:. ${ }^{2}$ Because most of these studies have used a two frame technique, in which only end systolic and end diastolic frames are examined,

Requests for reprints to Dr J R Dawson, St George's Hospital, Blackshaw Road, London SW17 0QT.

Accepted for publication 14 October 1987 regional asynchrony (abnormal timing of wall motion) cannot be recognised and documented although it is well known as a consequence of experimental ischaemia. ${ }^{34}$

In this study we have used frame by frame analysis of left ventricular contrast cineangiograms to analyse the effects of an episode of angina on both the amplitude and timing of regional left ventricular wall motion. By constructing segmental pressure walldisplacement loops ${ }^{5}$ we have been able to explore the physiological consequences of the regional hypokinesis and asynchrony that develop with angina on energy transfer from the myocardium to the circulation. 


\section{Patients and methods}

\section{PATIENTS AND THE CATHETERISATION PROCEDURE}

Studies were performed during diagnostic cardiac catheterisation in 24 patients being investigated for the symptom of chest pain thought to be angina. Patients gave written consent to the study that had been approved by the ethics committee of the Brompton Hospital. There were two groups of patients. One group comprised 14 men (mean age 51 years, range 42-68 years) with chronic stable exertional angina. Six of these patients had had previous myocardial infarction. Coronary arteriography showed that all had obstructive $(>70 \%)$ coronary artery lesions (eight single, one double, and five triple vessel disease). The other group comprised 10 individuals (six men, four women, mean age 50 years, range 32-62 years) who proved to have a normal coronary arteriogram. All patients in this group had normal electrocardiograms, chest $x$ rays, and $M$ mode and cross sectional echocardiograms and they were therefore considered to be a control group with normal left ventricular function.

Catheterisation was performed from the right femoral artery and vein using the Seldinger method. Immediately after arterial cannulation heparin (50 u/ $\mathrm{kg}$ ) was given. Multiple views of the coronary arteries were obtained by Judkins' technique. After coronary arteriography an 8 French gauge Gaeltec catheter was positioned in the left ventricle by the long sheath technique. ${ }^{6}$ The Gaeltec catheter combines a tip manometer with a fluid filled lumen which is used for calibrating the micromanometer and for injection of radio-opaque contrast material. Left ventriculography with a cine speed of 50 frames a second was performed in the $30^{\circ}$ right anterior oblique projection with $50 \mathrm{ml}$ of Urografin injected at a flow rate of $12 \mathrm{ml} / \mathrm{s}$. High fidelity left ventricular pressure was recorded during contrast injection.

In the 14 patients with coronary artery disease an episode of angina was provoked by rapid atrial pacing with a Zucker bipolar catheter positioned in the right atrial appendage. Pacing was started at 100 beats per minute and increased by 10 beats per minute every two minutes up to a maximum of 150 beats per minute. The patients were asked to indicate the level of angina at which they would normally discontinue activity or stop to take a glyceryl trinitrate tablet. At this point atrial pacing was abruptly terminated and, within 5-10 seconds, a second left ventricular cineangiogram was performed, with the patient in sinus rhythm and with the same radiographic projection, quantity of contrast material, and flow rate as before. In all studies 15 minutes were allowed to elapse between coronary arteriography and left ventricu- lography. In the patients with coronary artery disease $\vec{c}$ a further 15 minutes were allowed to elapse between $\overrightarrow{\vec{F}}$ initial ventriculography and the onset of atrial pacing.

The angiograms were calibrated by measuring the movement of the catheter tip when the catheter table was displaced by $10 \mathrm{~cm}$.

ANALYSIS OF DATA Cineangiograms were digitised frame by frame with a hand held cursor. ${ }^{7}$ Frames were related to each other $\vec{\omega}$ by a fixed external reference point. Beats chosen for analysis had occurred within five cycles of the onset of radiographic contrast medium first entering the ventricle. Extrasystoles and postextrasystoles were excluded from analysis. The end diastolic frame was identified by a QRS complex marker produced by an electrocardiographically gated light emitting diode in the shutter plane assembly of the cine camera. Cavity volume was determined by the area-length method. ${ }^{8}$ The time of mitral valve opening was estimated to occur when unopacified blood first entered the left ventricle during diastole.

To study regional wall motion the end diastolic frame was divided into 40 separate points, or segments, equally spaced around the perimeter of the left ventricular cavity. The frame with the minimum area was taken and the points nearest to each of the $\mathbf{4 0}$ points on the end diastolic frame were identified. A line was then drawn between each pair of points. For each of the 40 lines a plot of endocardial position as a function of time was generated. For each of the forty lines thus generated we constructed a plot of endocardial position as a function of time. The $40 \vec{\Phi}$ plots were combined to produce isometric and contour displays so that the amplitude and timing of wall motion for the ventricle overall could be appreciated.

A pressure-endocardial displacement loop was also 응 constructed for each of the $\mathbf{4 0}$ segments. The area of such a loop is a measure of the external work 을 performed during the cardiac cycle by that segment $D$ of the ventricle. ${ }^{9}$ The maximum work that can be done by a segment working over the observed range $\bar{N}$ of pressure and endocardial displacement is the product of the two-that is the area of the rectangle $\mathrm{N}$ that just encloses the loop. The ratio (expressed as a $\mathrm{W}$ percentage) between the measured area of the loop to $\bar{\gamma}$ the area of the rectangle just enclosing the loop is cycle efficiency. This is an index that relates energy $\mathbb{D}$ transfer between the relevant region of the myocardium and the circulation.

We measured the following:

(a) Left ventricular end diastolic volume (synchronous with the onset of the $Q$ wave on the $Q$ electrocardiogram), minimum volume, and ejection fraction. 
(b) Left ventricular peak systolic pressure and end diastolic pressure.

(c) For each of the forty perimeter points we measured the timing (to the nearest $20 \mathrm{~ms}$ ) of onset of inward movement of endocardium relative to the end diastolic frame according to a previously described algorithm ${ }^{10}$ and the timing of peak inward displacement of endocardium relative to the timing of minimum cavity volume.

(d) Overall amplitude of movement (to the nearest $0.5 \mathrm{~mm}$ ) during the cardiac cycle for each of the 40 segments.

(e) For each of the 40 pressure-displacement loops we calculated segmental work $\left(\mathrm{J} / \mathrm{m}^{2}\right)$ and cycle efficiency ( $\%)$.

\section{IDENTIFICATION OF ABNORMAL REGIONAL}

WALL MOTION

The angiograms and pressures recorded in the control group were used to derive normal values for the timing and amplitude of endocardial movement for each perimeter point and for work and efficiency for each segment.

In the patients with coronary artery disease: a region was considered to show hypokinesis if, in three or more adjacent segments, the amplitude of endocardial movement was below the lower $95 \%$ confidence limit of the range for the same segments in the control group; a region of hyperkinesis was identified when in three or more adjacent segments the amplitude of motion was above the upper $95 \%$ confidence limit; and a region of asynchrony was deemed to be present if in three or more adjacent segments the timing of endocardial motion was outside the $95 \%$ confidence limits of the range for the same segments in the control group.

Two types of asynchrony were identified: (a)
Table 1 Left ventricular function

\begin{tabular}{llll}
\hline & & \multicolumn{2}{l}{$\begin{array}{l}\text { Coronary artery } \\
\text { disease }(n=14)\end{array}$} \\
\cline { 3 - 4 } & $\begin{array}{l}\text { Controls } \\
(n=10)\end{array}$ & Rest & Angina \\
\hline $\begin{array}{l}\text { LV systolic pressure } \\
\text { (mm Hg) }\end{array}$ & $149(29)$ & $141(34)$ & $\begin{array}{l}146 \\
(31)\end{array}$ \\
$\begin{array}{l}\text { LV end diastolic pressure } \\
\text { (mm Hg) }\end{array}$ & $16(6)$ & $23(8)$ & $\begin{array}{l}27 \\
(9)^{\star}\end{array}$ \\
$\begin{array}{l}\text { LV end diastolic volume } \\
\text { (ml) }\end{array}$ & $146(47)$ & $167(37)$ & $\begin{array}{c}169 \\
(38)\end{array}$ \\
$\begin{array}{l}\text { LV minimum volume (ml) } \\
\text { Ejection fraction (\%) }\end{array}$ & $26(13)$ & $50(31)$ & $\begin{array}{c}57 \\
(32)^{\star}\end{array}$ \\
Heart rate (beats/min) & $71(15)$ & $69(17)$ & $\begin{array}{c}(14) \dagger \\
80\end{array}$ \\
& & $71(12)$ & $(18) \dagger$ \\
\hline
\end{tabular}

${ }^{\star} \mathrm{p}<0.05 . \dagger \mathrm{p}<0.01$ angina $v s$ resting values.

delayed onset of inward endocardial motion during systole; (b) premature or delayed timing of peak inward displacement relative to the time of minimum cavity volume.

\section{STATISTICAL METHODS}

Results are expressed as mean (1 SD). Differences between means were compared by Student's $t$ test. We used linear regression to examine relations between variables.

\section{Results}

\section{CONTROL GROUP}

Pressure and volume (table 1)

In the 10 individuals with normal left ventricular function the left ventricular peak systolic pressure was 149 (29) $\mathrm{mm} \mathrm{Hg}$ and left ventricular end diastolic

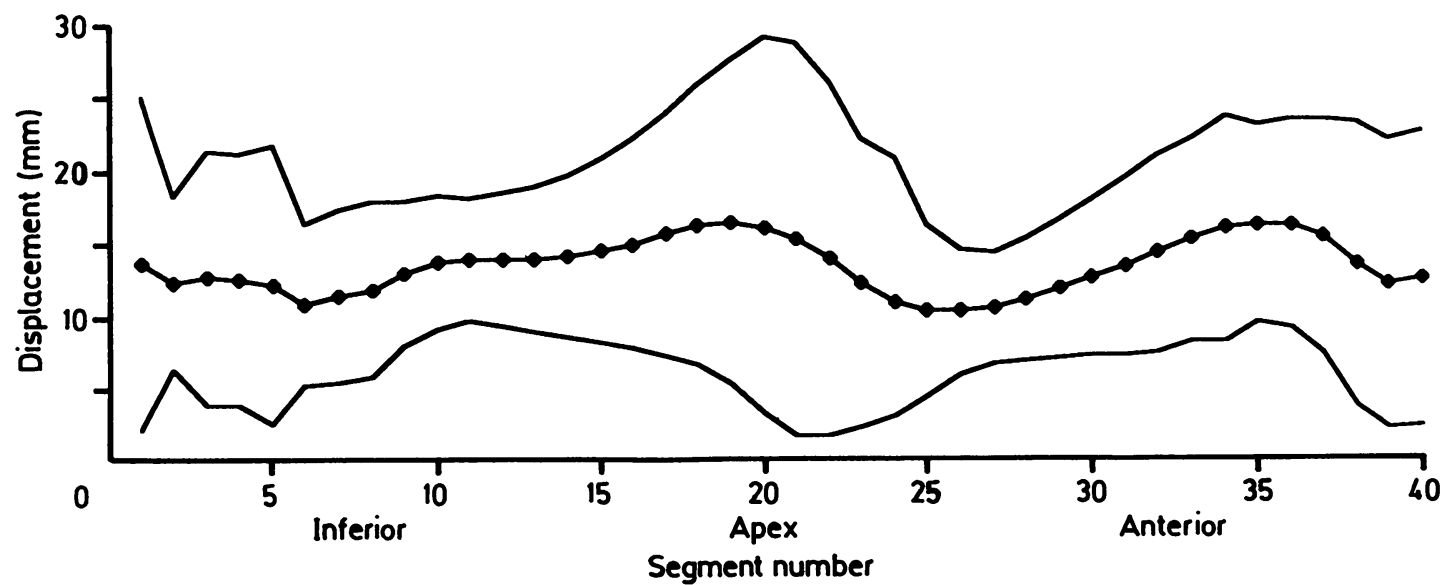

Fig 1 Values for maximum endocardial displacement (mean (2 SD)) during the cardiac cycle for each of the 40 perimeter segments in the control group. 
pressure was 16 (6) $\mathrm{mm} \mathrm{Hg}$. Left ventricular end diastolic volume was $146(47) \mathrm{ml}$, minimum volume $26(13) \mathrm{ml}$, and ejection fraction was $83(3) \%$. The heart rate during angiography was 71 (15) beats per minute.

\section{Regional amplitude of wall motion}

Figure 1 shows the amplitude of wall motion for each of the 40 segments. With a right anterior oblique projection and a fixed external reference point the overall amplitude of wall motion varies between different regions of the ventricle. The smallest amplitude of motion (10 (2) $\mathrm{mm}$ ) was found in the apical and distal anterolateral segments (points 2330 ) and the largest amplitude of motion (16 (4) $\mathrm{mm}$ ) in the proximal anterolateral segments (points 33-37) and distal inferior segments (points 17-21).

\section{Timing of regional wall motion}

Figure 2 shows the timing of wall motion for each of the 40 perimeter points. Panel (a) shows the timing of onset of inward movement relative to end diastole. Panel $(b)$ shows the timing of peak inward displacement relative to the time of minimum cavity volume. As with wall motion amplitude, regional

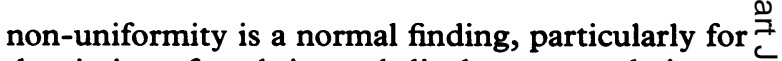
the timing of peak inward displacement relative to minimum cavity volume. In the control group peak inward displacement in inferior segments occurred $\overline{0}$ up to $140 \mathrm{~ms}$ after minimum cavity volume, whereas 흘 in anterolateral segments peak inward displacement $\frac{\bar{c}}{2}$ was seen up to $100 \mathrm{~ms}$ before minimum cavity $\underset{\propto}{\mathscr{D}}$ volume. Inspection of the isometric display for an individual subject (fig 3a) makes this non-uniformity in the timing of peak inward displacement obvious. Except in the apical segments (17-26) there was much greater uniformity in the timing of inset of $\stackrel{\circ}{\circ}$ inward wall motion relative to the end-diastolic frame. This is most clearly shown on a contour 0 display from an individual subject (fig 3b). $\dot{\omega}$ Synchronous inward movement is shown by vertical $\omega_{0}$ orientation of the contour lines.

\section{Pressure-displacement loops}

Figure 4 shows the work $(a)$ and cycle efficiency $(b)$ of each of the $\mathbf{4 0}$ perimeter segments. Again regional $\frac{3}{S}$ non-uniformity was a normal finding. Regional efficiency ranged from 51 to $70 \%$ and was lowest in the proximal anterior segments $(30-40)$.
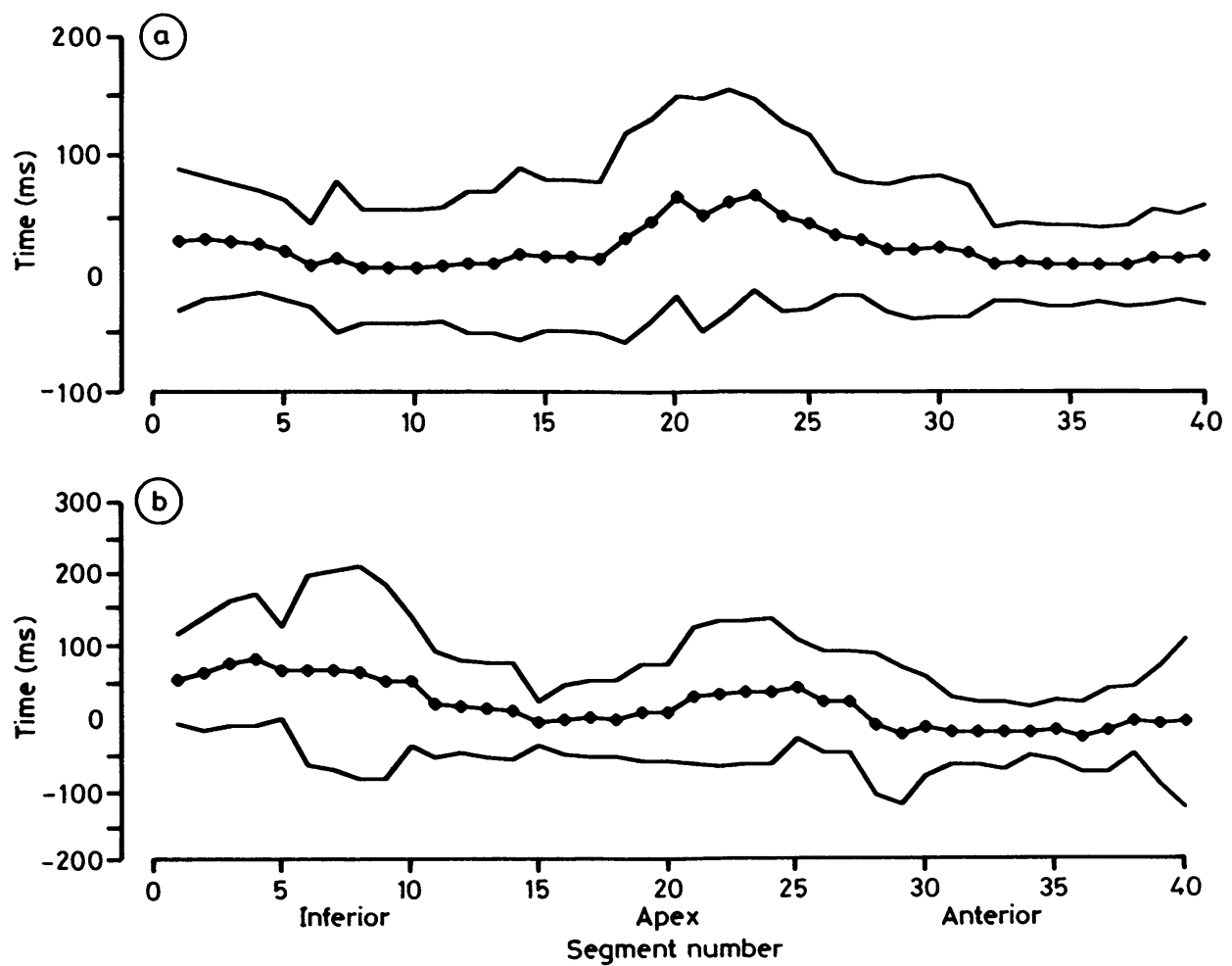

Fig 2 Normal values (mean (2SD)) for the timing of onset of inward endocardial displacement relative to end diastole $(a)$ and of peak inward endocardial motion relative to minimum ventricular volume (b) for each of the 40 perimeter segments in the control group. 

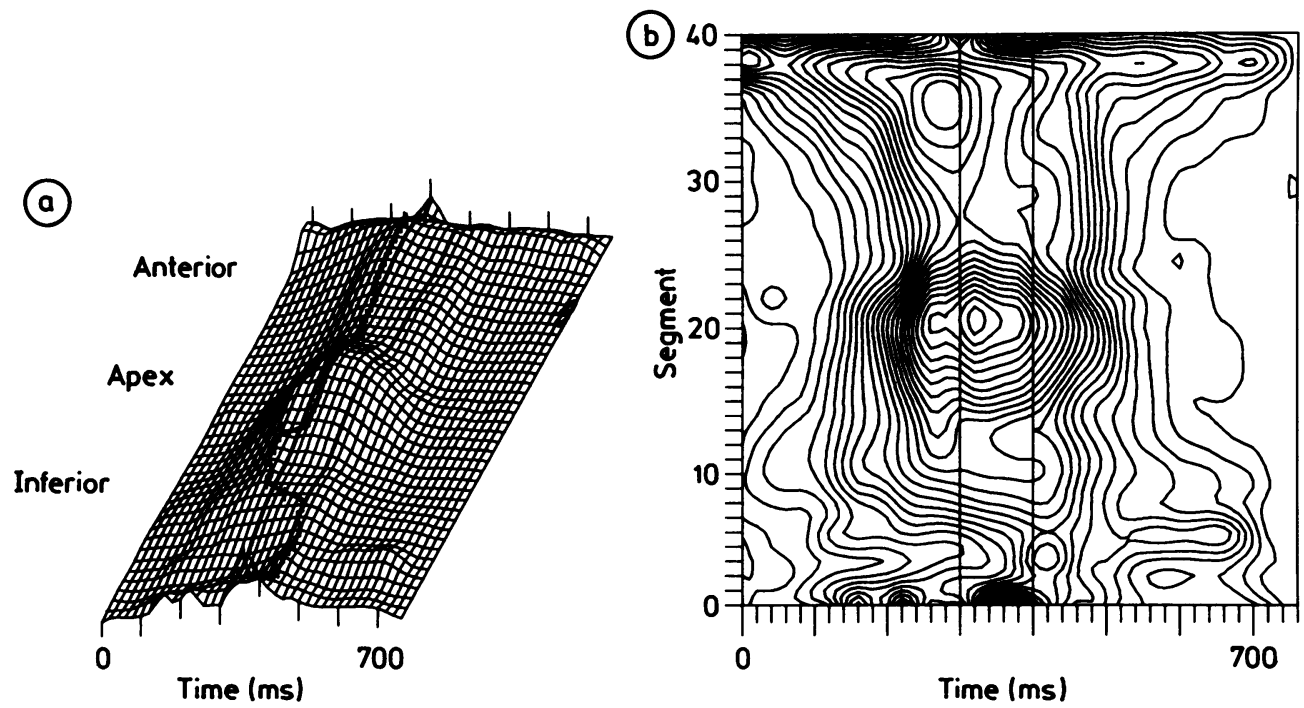

Fig 3 An isometric plot (a) from a control. The display is produced by stacking, one above the other and slightly offset, the plots of wall displacement against time for each of the 40 segments. The diagonal lines are isochrones (20 ms intervals) linking points synchronous in time. The accentuated isochrones mark the timing of minimum ventricular volume (left side of plot) and the timing of mitral valve opening. The other accentuated line indicates the timing of peak inward movement for each segment and shows that regional non-uniformity is a normal finding. (b) A contour plot taken from a control. The contour lines (1 mm spacing) join points displaced by the same amount relative to their position at end diastole. The two vertical lines mark the timing of minimum cavity volume (left hand) and of mitral valve opening. In normal subjects the contour lines are closely spaced during ejection and early diastole and tend to run vertically.

PATIENTS WITH CORONARY ARTERY DISEASE Overall left ventricular function (table 1)

In the 14 patients with coronary artery disease, left ventricular systolic and end diastolic pressures at rest were 141 (34) $\mathrm{mm} \mathrm{Hg}$ and 23 (8) $\mathrm{mm} \mathrm{Hg}$ respectively. Resting left ventricular end diastolic volume was 167 (37) $\mathrm{ml}$, ventricular minimum volume 50 (31) $\mathrm{ml}$, and ejection fraction 71 (12)\%.

An episode of angina produced small but statistically significant increases $(4(7) \mathrm{mm} \mathrm{Hg}(\mathrm{p}<0.05)$ ) in left ventricular end diastolic pressure and minimum volume $(7(11) \mathrm{ml}(\mathrm{p}<0.05))$ and a fall in ejection fraction $(5(7) \%(p<0.01))$. Heart rate at rest was 69 (17) beats/min and during angina it was 80 (18) beats/min $(\mathrm{p}<0.01)$.

\section{Amplitude and patterns of wall motion at rest}

In four patients the amplitude and timing of wall motion at rest was within the normal range for all the 40 perimeter points. In the remaining 10 patients, 12 abnormal resting regions were seen. Late onset of endocardial motion during systole was the commonest abnormality and was seen in 11 regions in nine patients. The number of affected segments ranged from three to 10 (8-25\% of cavity perimeter), with a mean of five segments. Delayed onset of inward wall motion was shown on the contour display by the diagonal (rather than the vertical) orientation of contour lines during early systole (fig 5). Six regions in five patients showed resting hypokinesis (mean number of affected segments nine (range 3-26). In all but one patient the region of resting hypokinesis occurred in a region that also showed late onset of inward endocardial motion.

No resting areas of abnormal timing of peak inward displacement relative to minimum cavity volume were identified.

\section{Effect of angina on wall motion}

The effects of an episode of angina on the amplitude and timing of left ventricular wall motion were complex. In two patients (one with a large area of resting hypokinesis and the other with normal wall motion at rest) no change was evident. In the remaining 12 patients 19 regions of abnormal wall motion developed with angina.

The commonest abnormality was the development of a region of hypokinesis in 12 regions in 10 patients. In seven instances hypokinesis developed in a region with normal amplitude of wall motion at rest. In the 

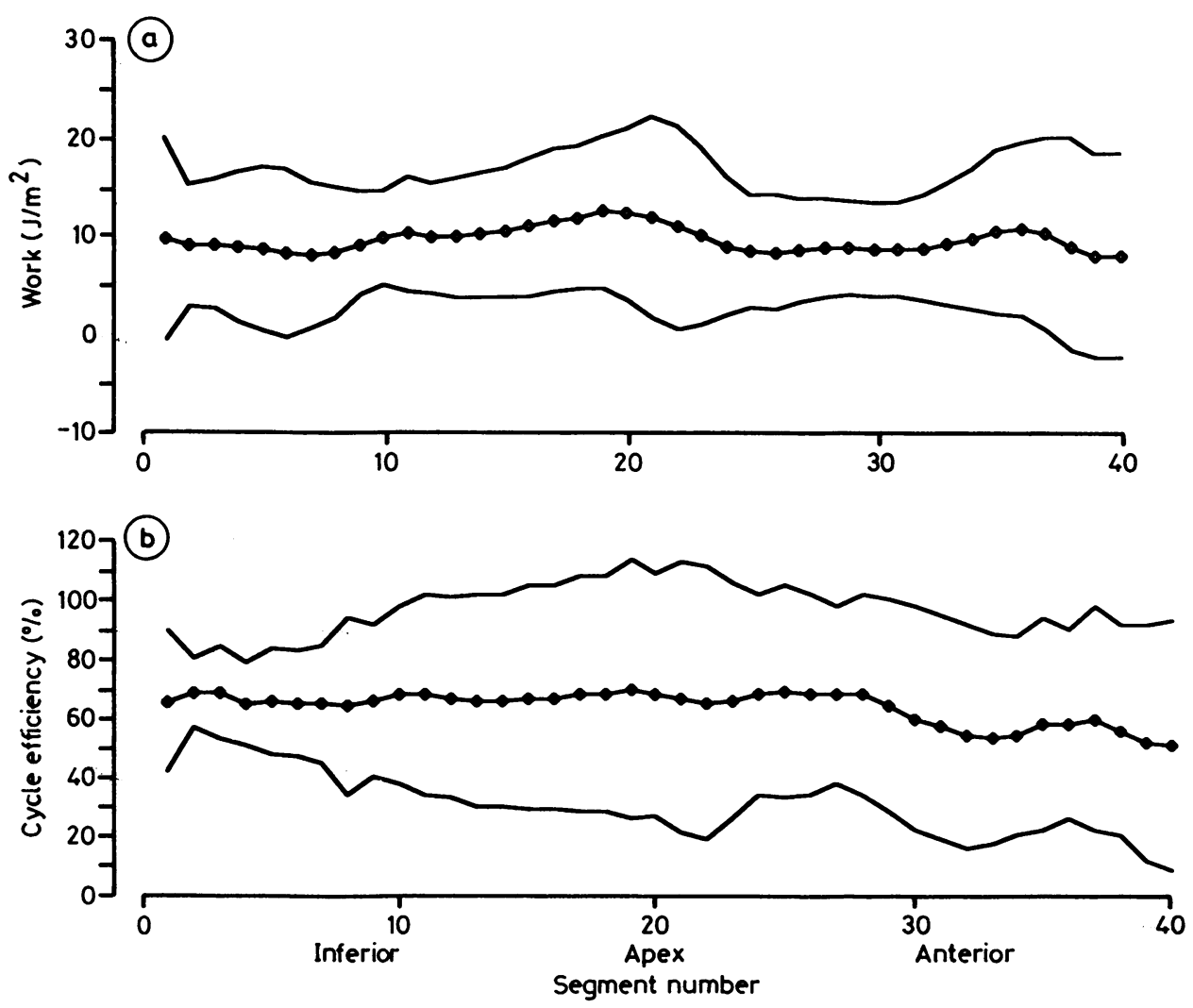

Fig 4 Normal values (mean (2 SD)) for segmental external work ( $a$ ) and cycle efficiency (b) for each of the 40 perimeter segments in the control group.

remaining five cases there was extension (by at least four segments) of a resting hypokinetic region. In the 10 patients the mean number of affected segments was 7 (3), significantly greater than the control value of 2 (3) segments $(p<0.001)$. In all but two instances the region of hypokinesis developed within a region that at rest showed delayed onset of inward endocardial motion during systole (diagonal contour lines) (fig 6). A region of inferior hyperkinesis was seen in one patient with single vessel disease affecting the left anterior descending artery who developed a region of anterior hypokinesis. This was thought to be a secondary compensatory phenomenon.

A second major abnormality, asynchrony with delayed peak inward endocardial displacement relative to minimum ventricular volume, was seen in eight regions in eight patients (fig 7). In two of the eight patients the amplitude of wall motion in the affected region remained normal but in six hypokinesis was also present. In these eight patients with asynchrony the mean number of affected segments was 6 (2) ( $\mathrm{p}<0.001$ vs control). The regions that developed asynchrony with angina were normal at rest in two cases, hypokinetic at rest in two cases, and showed late onset of inward endocardial motion at rest in four cases. Four of these eight patients also developed regions (mean number of segments 5 , range 3-10) of premature peak inward endocardial displacement relative to minimum cavity volume elsewhere in the ventricle. Two of these four cases occurred in patients with single vessel disease. In these two cases the region of premature peak inward endocardial displacement was identified in a normally perfused region of myocardium. Premature peak inward displacement was thus thought to be a secondary phenomenon.

The development of new regions showing late onset of inward endocardial motion (or diagonal contours) was not a feature of an episode of angina. In the 14 patients the mean number of segments showing this abnormality was 4 (4) at rest and 4 (5) during angina (NS). 


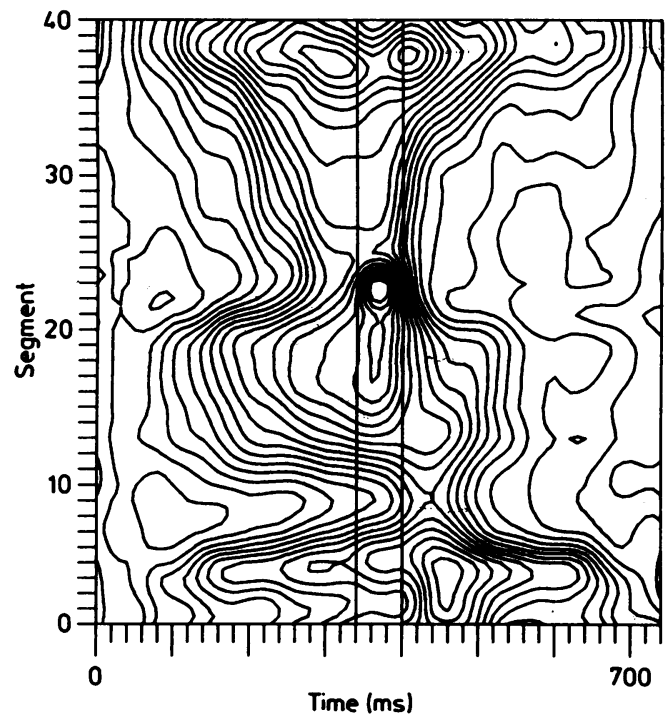

Fig 5 A contour display derived from the cineangiogram at rest of a patient with coronary artery disease. The contour lines run diagonally in the inferior segments indicating delayed onset of inward endocardial motion in this region.

\section{Pressure-displacement relations at rest and with angina}

Further physiological consequences of an episode of angina were identified from an analysis of the pressure displacement loops (table 2). In regions developing hypokinesis alone, segmental external work was reduced as a result of diminished amplitude of wall motion but cycle efficiency was conserved or even rose slightly. In regions showing asynchrony with delayed timing of peak inward endocardial motion the pressure-displacement loops became distorted (fig 8). The distorted shape of the loops reduced segmental cycle efficiency and hence segmental external work despite there being normal amplitude of wall motion in many instances.

In four cases the development with angina of asynchrony in a region of the ventricle subtended by a diseased coronary artery was accompanied by secondary abnormalities in a distant region of the ventricle with apparently normal coronary perfusion. These abnormalities which most obviously affected the proximal anterolateral wall took the form of premature timing of peak inward endocardial displacement which produced distorted pressuredisplacement loops. As with asynchrony caused by delayed timing of peak inward endocardial displacement the result of such an alteration to the normal configuration of a pressure-displacement loop tended to reduce efficiency of energy transfer from the affected region of myocardium.
Relations between global and regional left ventricular function

Changes in regional left ventricular wall motion produced by an episode of angina showed little correlation with conventional global indices of left ventricular function. There was no relation between the number of segments developing asynchrony and changes in ejection fraction or left ventricular end diastolic pressure. Similarly, there was no relation between the number of segments developing hypokinesis and changes in left ventricular end diastolic pressure. Only the number of segments developing hypokinesis and the change in ejection fraction with angina showed a slight association $(r=0.7, p<$ 0.05).
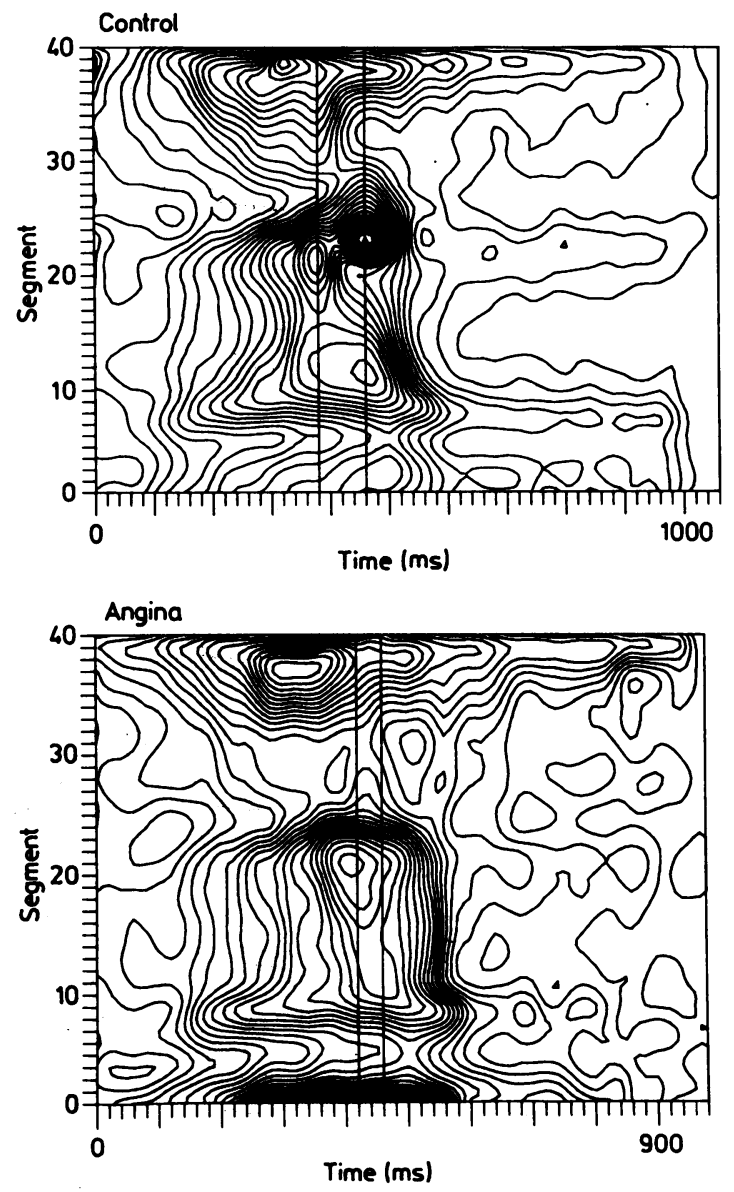

Fig 6 Contour plots taken from a patient at rest (top panel) and during angina (bottom panel). Layout as in fig $3 b$. An anterior region of delayed onset of inward motion, shown by diagonal contour lines, is evident in the plot at rest. This became hypokinetic with angina. 


\section{Discussion}

This study shows that regional disturbances of left ventricular wall motion associated with pacing induced angina are complex, causing changes both in timing and amplitude of wall motion. The disturbances depend, in part, on the wall motion pattern present under control conditions. Left ventricular contrast angiography with frame by frame digitisation of cavity outlines seemed the technique most suited to illustrate such complex disturbances because it gives a comprehensive display of both the amplitude and the timing of regional wall motion.

During the normal cardiac cycle energy is transferred from the myocardium to the circulation. The amount of energy transferred depends not only on the amplitude of wall motion in the region in question, but also on the efficiency of energy transfer, which is influenced by the timing of regional motion. These aspects can be studied in detail by constructing pressure-displacement loops, similar to pressuredimension loops which we have previously described. ${ }^{89}$ It appears that local energy transfer may fall with angina either because the amplitude or the timing of regional wall motion becomes abnormal.

In most patients an episode of angina was associated with the development of abnormal wall motion. We cannot tell whether this was caused directly by the angina or whether there was a separate effect of the tachycardia used to provoke the angina and which persisted as a slightly higher heart rate at the time of the second angiogram. The commonest abnormality was a fall in amplitude (hypokinesis) which was seen in 10 patients. In four out of the five patients with single vessel coronary artery disease there was hypokinesis in the region subtended by the affected vessel, suggesting that it was the direct result of local ischaemia. Although regional work fell with hypokinesis, cycle efficiency, a measure of the synchrony of wall motion, was either unchanged or even increased slightly. In contrast, striking asynchrony appeared in eight patients, with peak inward wall motion being delayed relative to minimum cavity volume. In two cases this was so extreme that peak inward displacement in the affected region actually occurred in the period of rapid ventricular filling after mitral valve opening. The method of display we used might have been affected by the development of these wall motion abnormalities, since a reduction in local amplitude may have led to some redistribution of sites on the endocardium among the $\mathbf{4 0}$ lines along which motion was assessed. The disturbances themselves were extensive, affecting a mean of six or seven segments, so it is unlikely that this effect led to any major distortion in delineating them. Pressure-displacement loops demonstrated that asynchrony was associated with reduced external work as a result of diminished cycle efficiency, although in many instances the amplitude of wall motion in the affected segments remained normal.

Hypokinesis and delayed peak inward endocardial displacement occurring with angina both seemed to be direct consequences of local ischaemia. The remaining abnormalities, one region of hyperkinesis and four with premature peak inward endocardial motion, appeared different and seemed to represent 
Table 2 Analysis of pressure-displacement loops

\begin{tabular}{|c|c|c|c|c|c|c|}
\hline & \multicolumn{2}{|c|}{ Hypokinesis $(n=6)$} & \multicolumn{2}{|c|}{$\begin{array}{l}\text { Asychrony with delayed peak } \\
\text { inward motion }(n=8)\end{array}$} & \multicolumn{2}{|c|}{$\begin{array}{l}\text { Asychrony with } \\
\text { premature peak inward } \\
\text { motion }(n=4)\end{array}$} \\
\hline & $\overline{\text { Rest }}$ & $\overline{\text { Angina }}$ & $\overline{\text { Rest }}$ & $\overline{\text { Angina }}$ & $\overline{\text { Rest }}$ & Angina \\
\hline Efficiency (\%) & $58 \quad(10)$ & $\begin{array}{ll}63(7) \\
\end{array}$ & $73(6)$ & $64(8)^{\star}$ & 63 (19) & $\begin{array}{l}53 \\
(16)\end{array}$ \\
\hline Work $\left(\mathrm{J} / \mathrm{m}^{2}\right)$ & $5.7 \quad(1.5)$ & $3.7(1.2)^{\star}$ & $8.6(1.7)$ & $5.8(1.7)^{\star}$ & $6.4 \quad(4.5)$ & $\begin{array}{r}5 \cdot 8 \\
(3 \cdot 4)\end{array}$ \\
\hline
\end{tabular}

${ }^{\star} \mathrm{p}<0.05$ angina $v$ rest.

secondary phenomena, because in patients with single vessel disease they developed in regions of the ventricle with normal perfusion. Similar disturbances have also been observed in patients with chronic coronary artery disease, where premature early out-
29

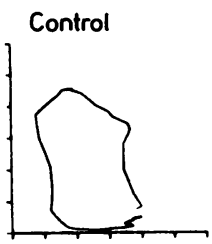

30

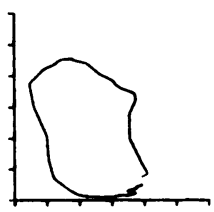

31

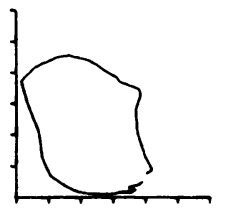

32

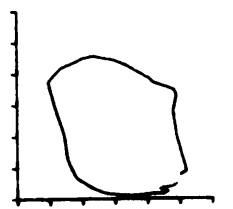

33

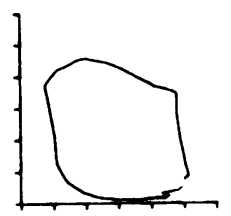

Angina

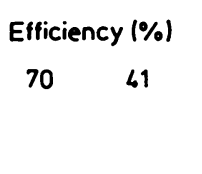

71

37

73

42

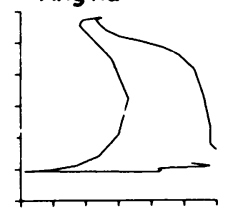

7

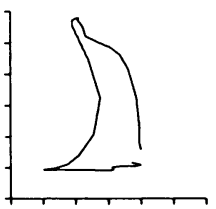

79

79
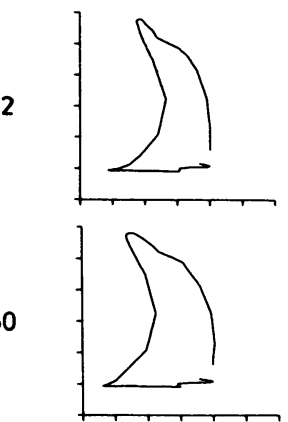

57

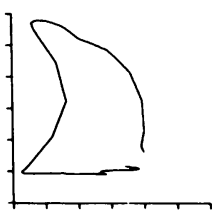

Fig 8 A sequence of pressure-displacement loops (segments 29-33) taken from a patient who developed an anterior region of asynchrony with delayed timing of peak inward endocardial displacement relative to minimum ventricular volume. For each loop pressure is plotted on the ordinate and wall displacement on the abscissa. During angina (right hand panel) the loops are distorted and cycle efficiency is diminished. ward motion is also found in regions with normal coronary supply and systolic function. ${ }^{7}$ Despite this, premature peak inward displacement was associated with reduced cycle efficiency and therefore overall energy transfer in affected segments, underlining the generalised nature of the disturbance to overall left ventricular function that occurred during an attack of angina. In the present study only a slight fall in ejection fraction and increases in end systolic volume and end diastolic pressure were seen during angina, and it seems that orthodox measures of global left ventricular function do not reflect the extensive abnormalities that were documented from observations of regional wall motion.

The pattern of wall motion during angina was related to that occurring under control conditions. In 10 out of the 12 regions of hypokinesis, with or without asynchrony, the angiogram at rest showed a pattern of diagonal contours in the affected region. The physical basis of this pattern is delay in the onset of inward endocardial motion, which in some regions did not begin until mid-ejection or even later. Such regions showed no outward movement during isovolumic contraction or early ejection; this strongly suggests that the timing of onset of tension development in these regions was normal, but that its magnitude was not great enough to cause inward wall movement until late in ejection when wall tension begins to fall. This delay was predominantly found in the mid-portions of the anterior and inferior walls where there is the least curvature and therefore wall tension is greatest for any given cavity pressure. The delay strongly suggests that even under resting conditions local function is compromised and that with an attack of angina this disturbance is simply accentuated. The distribution and time relations of this pattern of motion differ sharply from the early outward motion occurring during isovolumic contraction and early ejection that is found in some patients with chronic coronary artery disease in whom the pattern is confined to the apex and inferior wall and where the subsequent velocity and amplitude of inward motion may be quite normal and consistent with local delay in the onset of tension development. ${ }^{11}$ 
In sharp contrast to hypokinesis, asynchrony developing during angina arose either in normal regions or in those showing hypokinesis or delayed onset of inward motion during ejection. Its appearance could not, therefore, be predicted from the resting pattern of wall motion so that its development seems to involve some undetermined additional factor that appears only with stress. Once established, we speculate that the abnormality becomes self perpetuating because prolongation of myocardial tension development into early diastole would, of itself, further interfere with coronary flow to the affected region of myocardium.

This study confirms that attacks of angina were accompanied by regional disturbances of ventricular function. It has further demonstrated that these disturbances are complex, causing abnormalities in the timing as well as in the amplitude of wall motion. Two distinct mechanisms, hypokinesis and asynchrony, appear to be responsible and they can operate either separately or in combination. Regions that develop hypokinesis during angina can be predicted from analysis of the resting pattern of wall motion, suggesting that their function is already compromised at rest. Those in which asynchrony develops cannot be predicted in this way, which suggests that an additional factor operates in an attack of angina.

This work was supported by the Brompton Hospital Waring Trust.

\section{References}

1 Sharma B, Goodwin JF, Raphael MJ, Steiner RE, Rainbow RG, Taylor SH. Left ventricular angiography on exercise. A new method of assessing left ventricular function in ischaemic heart disease. $B r$
Heart J 1976;38:59-70.

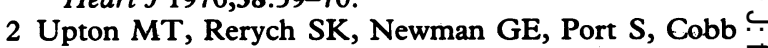
FR, Jones RH. Detecting abnormalities in left ven- $\overrightarrow{\bar{N}}$ tricular function during exercise before angina and $\rightarrow$ ST-segment depression. Circulation 1980;62:341-9.

3 Tyberg JV, Parmley WW, Sonnenblick EH. In vitro studies of ventricular asynchrony and regional hypoxia. Circ Res 1969;25:569-79.

4 Forrester JS, Tyberg JV, Wyatt HL, Goldner S, 贯 Parmley WW, Swan HJC. An analysis of segmental ischaemic dysfunction utilizing the pressure-length loop. Circulation 1974;49:748-54.

5 Gibson DG, Brown DJ. Use of echocardiography in the evaluation of left ventricular function. Proc Roy Soc Med 1974;67:140-2.

6 Brooksby IAB, Swanton RH, Jenkins BS, Webb- OS Peploe MM. Long sheath technique for introduction $\omega$ of catheter tip manometer or endomyocardial bioptome into left or right heart. $\mathrm{Br}$ Heart $J$ 1974;36: 908-12.

7 Gibson DG, Prewitt TA, Brown DJ. Analysis of left ventricular wall movement during isovolumic relaxation and its relation to coronary artery disease. $\mathrm{Br}$ Heart $J$ 1976;38:1010-9.

8 Dodge HT, Sandler H, Baxley WA, Hawley RR. $\overrightarrow{0}$ Usefulness and limitations of radiographic methods $\infty_{\infty}^{\infty}$ for determining left ventricular volume. Am J Cardiol ${ }^{\circ}$ 1966;18:10-24.

9 Gibson DG, Brown DJ. Assessment of left ventricular systolic function in man from simultaneous echocar-o diographic and pressure measurements. Br Heart $J$ 1976;38:8-17.

10 Hammermeister KE, Gibson DG, Hughes D. Regional $\stackrel{2}{\vec{F}}$ variation in the timing and extent of left ventricular wall motion in normal subjects. Br Heart $J$ 1986;56: 226-35.

11 Gibson DG, Doran JH, Traill TA, Brown D.J. Abnormal left ventricular wall movement during early $\vec{\Phi}$ systole in patients with angina pectoris. $\mathrm{Br}$ Heart $J$ 1978;40:758-66. 